\title{
UNA CRITICA DE LA IMAGEN DE ESPAÑA EN LA LITERATURA DE VIAJES: GIUSEPPE BARETTI
}

En agosto de 1760, Giuseppe Banetti partió de Londres con el propósito de visitar la Península Ibérica por primera vez en un viaje que tenía como destino final su tierra natal, Piamonte. Residente en Londres desde 1751, Baretti había llegado a intimar con las figuras literarias inglesas más eminentes, y, en efecto, fue debido al consejo del Dr. Samuel Johnson por lo que decidió prestar especial atención a su paso por España. La primera edición de A Journey from London to Genoa through England, Portugal, Spain, and France salió en Londres en 1770, cuando ya su autor era Secretario de Correspondencia Extranjera de la Real Academia de Pintura, Escultura y Arquitectura de Inglaterra. El enfoque principal era el de instruir al público inglés sobre cómo apreciar la cultura y la sociedad españolas: “No tengo mejor disculpa que añadir, para explicar la confianza con la cual presento a esta nación ilustrada estos dos volúmenes, que la de que las relaciones de España hasta ahora publicadas en inglés se juzgan en general muy imperfectas» ( II have not a better apology to offer for my confidence in presenting this enlightened nation with these two volumes, than that the accounts of Spain hitherto published in the English language, are in general adjudged to be very imperfect») ${ }^{1}$. Este libro

1 Giuseppe Baretti, A Journey from London to Genoa through England, Portugal, Spain, and France (London: T. Davis and L. Davis, 1770), I, v. En adelante, las referencias a esta obra se darán en el texto. A Journey from London to Genoc gozó de una inmediata popularidad, siendo reeditada dos veces más en Londres el mismo año 1770. Una traducción francesa apareció en 1776 (Amsterdam) y una alemana en 1772 (Leipzig). No se editó en italiano hasta 1830 (Milán), indudablemente porque las numerosas 
presenta una recapitulación de cartas que aparecieron en sus Lettere familiari di Giuseppe Baretti a suoi fratelli Filippo, Giovanni e Amadeo (Milán, 1761), más observaciones sobre España motivadas tanto por la visita de 1760 como por otra de $1768^{2}$.

Patente en A Journey from London to Genoa es la esperanza del autor de que hubiera (cayudado eficazmente a la imaginación del lector para que se hiciera una idea de los habitantes) ( $I$, vi) (“effectually assisted the imagination of [the] reader to form an idea of the inhabitants»). Lamentaba la falta de esmero e imparcialidad tan prevalecientes en la literatura contemporánea de viajes. No obstante la nacionalidad de los viajeros, Baretti no creía que éstos habian sometido a prueba los prejuicios o suposiciones tácitas que dictaban comentarios demasiado ligeros e imposibles de comprobar. En cierto sentido, A Journey from London to Genoa escudriña la validez de mucha de la crítica literaria de la época, sobre todo la idea común del «buen gusto» literario. Para Baretti, los prejuicios y conceptos falsos presentes en la mayoría de las relaciones de viajes, inclusive las de las más renombradas figuras literarias, reflejaban una credulidad ingenua y una falta de documentación histórica y filológica inadmisibles ${ }^{3}$.

ediciones de Lettere familiari incluian parte de su contenido. Me he permitido traducir al español las citas de la obra de Baretti.

2 Para estudios generales de la vida y obra de Baretti, véanse: Mario Fubini, Dal Muratori al Bareti; studi sulla crítica e sulla cultura del Settecento (Bari, 1954); N. Jonard, Giuseppe Baretti (1719-1789). L'homme et l'oeuvre (Clermont.Ferrand, 1963). Como relación biográfica, es informativa de la Lacy Collison-Morley, Giuseppe Baretti. With an Account of His Literary Friendships and Feuds in Italy and in England in the Days of Dr. Iohnson (London. 1909).

3 Para la imagen de España en las relaciones de los viajeros ingleses del siglo XVIII, véanse mis estudios, “From Caricature to 'Objectivity': English Travel Accounts of Spain, 1700-1730", Revista Canadiense de Estudios Hispánicos: "An Ambiguous Image: English Travel Accounts of Spain, 1750-1787», Dieciocho; "A Modified Image: English Travel Accounts of Spain, 1788-1808), Dieciocho, que serán publicados en 1978-1979. Véanse también, John Walter Stoye, English Travellers Abroad (1604-1667) (London, 1952); José García Mercadal, España vista por los extranjeros, I-III (Madrid, 1917-1919); Julián Juderias, La leyenda negra (Barcelona, 1926); Sverker Arnoldsson, La leyenda negra (Göteborg, 1960); y William S. Malthy, The Black Legend in England (Durham, 1971). Siguen siendo las bibliografias más completas de relaciones de viajes por la Península: Arturo Farinelli, Viajes por España y Portugal (Madrid, 1920); Viajes por España y Portugul. Suplemento (Madrid, 1930); y R. Foulché Delbose, Bibliographie des voyages en Espagne et en Portugal (París, 1896). Véaso también F. Aguilar Piñal, "Relatos de viajes de extranjeros por la España del siglo XVIII. Estudios realizados hasta el presenten, Boletín del Centro de Estudios del Siglo XVIII, núms. 4-5, 1977, págs. 203.208. Una 
La imagen que Europa tenía de España le facilitó a Baretti un punto de partida en su ataque a la crítica histórica y literaria en general y a la literatura de viajes en particular. Como caso ejemplar, escogió a Madama d'Aulnoy, ya que sus comentarios sobre España habían influido considerablemente en los escritos de otros: "Se relata en los viajes que hizo Madama d'Aulnoy por España que la ley española considera a cualquier bastardo criado en la Casa de Expósitos de Madrid como un caballero. Esta aserción ha sido repetida con credulidad por los autores del Dictionnaire Encyclopédique. Pero no es cierto; un bastardo sigue siendo bastardo tanto en Madrid como en otros lugares... Es algo sorprendente cómo aquellos señores doctos pudieron basar en tan poca autoridad un hecho de una naturaleza tan singular» (II, 308-309) ( (It is said in Madam d'Aulnoy's travels through Spain, that every bastard brought-up in the foundling-Hospital at Madrid, is looked upon as a gentleman by the Spanish law. This assertion the authors of the Dictionnaire Encyclopédique have credulously repeated. But the fact is not true; a bastard is as much a bastard in Madrid as any where else... How those learned gentlemen could rest upon so slender an authority a fact of so singular a nature, is pretty surprising"). Estos conceptos falsos, comunes en la literatura de viajes, resultaban de la “inatención con la cual los viajeros cruzan paises, aun los que lo hacen con las plumas en la mano» (II, 192-193) («inattention with which travellers cross countries even those who do so with their quills in their hands»). Dada la práctica difundida y más o menos sancionada de plagiar, no había quien se sorprendiera de ver transmitirse las mismas perogrulladas y errores. Tal era así que a los españoles se les presentaba tradicionalmente como «altivos, graves e indolentes; a los franceses como volubles, confiados y habladores; a los italianos como astutos, celosos y supersticiosos; a los ingleses como inciviles, poco hospitalarios y filosóficos» (II, 192-193) (“proud, grave, and idle; the French volatile, confident and talkative; the Italians cunning, jealous, and superstitious; the English rude, inhospitable, and philosophical»). No era sólo una cuestión de inatención a detalles, sino que la mayoría de los viajeros cometían a sabiendas los pecados de pedantería y erudición superficial: « Pensemos en los miles y miles que han visitado Grecia y Turquía siglo tras siglo! ¡Pensemos en su habilidad para describir piedras rotas, copiar inscripciones desfiguradas, o desenredar la política del Diván y las intrigas del Serrallo! Sin embargo, ninguno de los inumerables

breve reseña de Lettere familiari es la de Giuseppe Carlo Rossi, "Gentes y paisajes de la España de 1760 en las cartas de Giuseppe Barettin, Actas del Primer Congreso Internacional de Hispanistas, ed. Frank Pierce y Cyril A. Jones (Oxford, 1964), páags. 437-442. 
viajeros ha podido descubrir una costumbre de Grecia y Turquía no menos singular que útil; y fue al fin y al cabo una mujer quien informó al occidente sobre la inoculación, para eterno honor de medio millón de señores viajeros) (II, 192-193) ("Think of the thousands and thousands who have visited Greece and Turkey century after century! Think of their abilities in describing broken stones and copying defaced inscriptions, or in unravelling the politicks of the Divan, and the intrigues of the Seraglio? Yet a custom of Greece and Turkey no less singular than useful, none of our numberless travellers could ever discover; and it was a lady at last who brought the western world acquainted with inoculation, to the eternal honour of half a million of travelling gentlemens).

Su impaciencia frente a los que denominó «caracterizadores de buen tono de las naciones modernas» (III, 1) («fashionable characterisers of modern nations») emanaba en gran parte del resentimiento que experimentaba al considerar los abundantes y equivocados dictámenes populares referentes a su tierra natal, Italia. Sería simplista, sin embargo, la conclusión de que sólo el resentimiento produjo su acrimonia contra el típico viajero de la época, porque desde el punto de vista filosófico de la Ilustración, Baretti insistía en que el hombre no poseía más cualidades intrínsecas que las que se estimaban comunes a todo hombre en general:

“El uso sobrio de la razón nos haría comprender con facilidad que la naturaleza humana siempre ha sido la misma por todo el mundo, aunque las naciones en las que se ha dividido el mundo pudieran por algún tiempo variar unas de otras en varios respectos, y ser alternadamente activas o inactivas, valientes o cobardes, cultas o ignorantes, honestas o deshonestas. El uso sobrio de la razón nos dirá qué virtudes particulares o vicios particula. res tomarán posesión a veces de esta a aquella parcela de tierra... para que luego pierdan su poder de grado en grado, cambien imperceptiblemente y dejen lugar a otras virtudes y otros vicios... Esta rotación es incesante... pero todavía los hombres siguen siendo esencialmente Ios mismos, todavía dotados de la misma susceptibilidad de calidades buenas y malas» (III, 3).

(Sober reasor would make us easily comprehend, that human nature has always been the same throughout the world, though the nations into which the world is divided, may temporarily vary from each other in several res. peets, and be alternately active or inactive, brave or cowardly, learned or ignorant, honest or dishonest. Sober reason will tell us that particular virtues and particular vices will at times take possession of this or that tract of land... then lose their power by degrees, shift away imperceptibly, and make room for other virtues and other vices... This rotation is incessant... but men still continue to be essentially the same, still endowed with the same susceptibility of good and bad qualities). 
Debido a esa rotación constante, Inglaterra habia llegado a ser la nación más próspera, ilustrada y poderosa del mundo. A pesar de eso, aun ella, como antes había sido el caso con Francia y España, perdería «el privilegio de preeminencia a través de una disminución de aquella actividad que les animaba durante cierto período» (III, 4) ("the privilege of preheminence by a relaxation of that activity which animated them during a certain periods).

Baretti alegaba que aun en el caso de que un país decayera, esto no sería motivo para concluir que se le hubiera acabado la posibilidad de distinguirse. Esa posibilidad o potencial siempre permanecía, de modo que tal país pudiera reenaltecerse un día por sus hazañas y obras. Imágenes como las del español indolente, el francés voluble, el italiano celoso o el inglés incivil recordaban a Baretti que era wobra del diablo difundir con ceptos tan erróneos, para que los hombres no se considerasen hermanos, sino que se condenasen y se odiasenn (III, 7) ( $\alpha$ the devil's business to spread such erroneous notions, that men may not consider themselves as brothers, but contemn and hate each other»). Si los españoles (hacen menos que los ingleses, los holandeses o cualquier nación moderna, no es por ninguna razón salvo que tienen menos que hacer. Pongámosles en una situación donde puedan ser más activos y lo serán. Lo juzgo así por lo que en efecto veo con mis ojos. Voy a verles en sus tiendas y otros lugares donde se trabaja... y encuentro que ellos hacen to que tienen que hacer con decorosa alogria $y$ rapidezn (III, 8) (udo less than the English, the Dutch, or any other present nation, it is for no other reason than that they have less to do. Put them in a condition to be more active, and more active they will be. I judge of this by what passes actually under my eyes. I: go to see them in their shops and other places where any work is going on... and 1 find that they do what they have to do with becoming cheerfulness and speed $n$ ). Lástima era que actitudes y opiniones incomprobadas como éstas hayan adquirido la apariencia de autoridad y respetabilidad; un error daba ocasión a otros todavía más perniciosos.

Culpables de estos desaciertos eran aquellos individuos que no discernian más que las virtuder y proczas de sus connacionales. Los viajeros franceses pecaban en este sentido más de lo comin; generalmente sus relaciones de viajes mostraban una falta casi completa de imparcialidad. Cuando se les antojaba, solían representar a una nación como irremediablemente depravada o totalmente inocente y noble. Estos viajeros sostenian que en Francia las costumbres, el comportamiento y la cultura eran los únicos que se podían clasificar como ilustrados (III, 315). Baretti volvía a insistir en la 
inexistencia de vicios o virtudes inherentes a una nación. Hacía presente a sus lectores lo que se decía de los franceses, a saber que éstos, además de poseer un natural alegre, eran muy hospitalarios tanto con conocidos como con forasteros y extranjeros. Tal vez fuera posible caracterizar de tal modo a los habitantes del sur de Francia, pero si se les comparaba, por ejemplo, con los normandos y los habitantes del norte del país, el dictamen no tendría mayor fundamento. En general, postulaba, la hospitalidad y la jovialidad variaban según los individuos, y añadía que aún si fuese cuestión de casos individuales, los españoles demostraban un grado de regocijo y afabilidad que probablemente no se podría hallar en los franceses. El viajero que estaba dispuesto a encontrar españoles que bailaban, cantaban y reían, los encontraría (IV, 146-148).

Dándose cuenta de que se le podia acusar de haber sido demasiado severo en su juicio de los franceses, Baretti no quiso admitir la posibilidad de que se le atribuyeran sentimientos galofóbos. Su larga estancia en Inglaterra, explicaba, no le había infectado con aquella ridícula antipatía hacia los [franceses] que alli es tan universal» (IV, 151) («that foolish antipathy toward the [French] which is there so universals). No se podia negar que Francia era "la nación más refinada de Europa» (IV, 151) ("the most polished nation in Europe»), y que toda Europa le debia gran parte de su ilustración.

En Extremadura, Baretti se enfrentó por primera vez con España, y su reacción inmediata fue favorable. Se hallaba, en realidad, aliviado de haber salido de Portugal, un país que llegó a disgustarle por varias razones ${ }^{4}$. Los portugueses eran quienes carecían de afabilidad, mientras que los españoles demostraban una «sensibilidad de corazón... fuertemente expresada en sus caras, universalmente muy expresivas tanto en los hombres como en las mujeres» (II, 110) («sensibility of heart... strongly expressed in their faces, universally full of meaning both in men and womens)). Era Extremadura una provincia empobrecida; se habían cortado todos los árboles, las dehesas estaban agotadas y los habitantes comían "poco, [estaban] cubiertos de trapos y se alojaban vilmente) (II, 128) (little, [were] covered with rags, and lodge[d] meanly"). Dadas estas adversidades, era de admirar lo amables, bien intencionados y sanos que eran los extremeños. Cerca de Trujillo, Baretti tropezó con un pastor que tenía un conocimiento sorprendente de

4 No sólo disgustaron a Baretti diferentes costumbres portuguesas, sino que, aparen. temente, fue insultado varias veces durante su paso por el país y, en cierta ocasión, apedreado. Véanse, por ejemplo, I, 122.131, 136, 186-190, 244, 274. 
antigüedades (II, 120). Hubo otros sucesos inesperados. Repetidas veces los españoles simpatizaban con los ingleses; éstos, en comparación con los que llamaban a aquellos Gavachos de Franceses» (II, 147-148), les parecian gente superior, aun a despecho de que se les considerase herejes. La compuobación de esta parcialidad anglófila se evidenciaba ea el grado de hospitalidad que ofrecían a los viajeros franceses e ingleses.

Otra cara de la vida española que impresionó a Baretti era la facilidad con que todos, y en particular los de más baja condición social, componían versos y canciones: "Aquí debo advertir que desde hace varios días he tenido la fuerte sospecha de que este país es un enjambre de cantores y poetas) (II, 180) ("Here I must tell you that for several days past I had entertained a strong suspicion, that this country swarmed with extempore singers and poets»). Algunos versos y canciones, claro está, podían ser tachados de obscenos, pero por lo común los cantores y poetas extemporáneos se expresaban con utanta gracia, y aun clegancia, que podrian compararse con algunos de nuestros árcades romanos» (11, 183) («such prettinesses, and even elegances, as would have done honour to some of our Roman Areadianss). Digna de atención era la absoluta falta de afectación. AI preguntarle a un campesino si conocian él y sus compañeros algunos romances, aquél respondió: «En mi aldea pocos libros hay. Todos cantan sin libros. Todos cantan y pocos leen» (II, 185). Baretti aseguraba que de ningura manera les era impedimento la escasez de lectura porque cantaban cualquier romance tan bien como los cantores más cultos, sino mejor que ellos. En este caso, los españoles se parecian a los toscanos, quienes también demostraban una gran habilidad para repentinas invenciones poéticas eantadas. Los españoles, en cambio, aunque menos dotados de una educación formal, superaban a los toseanos en cuanto a su genio creador y su sulil manejo del idioma (II, 185). Tan seduetoras exan las múltiples imágenes poéticas de estas canciones rústicas que Baretti acompañaba a los cantores en sus serenatas a las jóvenes (III, 216).

La civilidad de los mendigos recibió comentarios igualmente favorables. En Extremadura Baretti presenció casos en que los pordioseros pedían limosna de una manera que parecia indicar más el deseo de recibir una palabra o un gesto amables que bienes temporales: Además de pedir limosna, [ellos] insistian en que se besaran sus crucifijos grasientos y sus Madonas. No [debe] dárseles nada si no se liene la intención de besar las imágenes. porque ellos toman mucho más a pecho al crédito de aquéllas que el deseo de poseer ochavos y tuartillos. Si se les dan buenas palabras en vez de dinero. fácilmente ellos le dejarán en paz; pero si se les da algo sin 
besar las imágenes o los crucifijos, tendrá mucho lenguaje obsceno aunque sea de mucha cuantía la limosna» (II, 268) («Besides asking your charity, [they] insisted upon your kissing their greasy crucifixes and Madonnas. Give nothing to them except you intend to kiss their images, because they have much more at heart the credit of those images, than are desirous of your ochavos and quartillos. If you give them good words instead of money, they will easily let you alone; but if you give anything and refuse to kiss, you will have a deal of foul language, be your alms ever so great»). Limosneros excesivamente piadosos, como éstos, eran los menos. Normalmente los mendigos eran corteses; no insistían ni porfiaban. Este dictamen no se limitaba únicamente a los pobres; en general los españoles no revelaban la arrogancia y xenofobia que les atribuian otros viajeros. El pueblo español no se permitía «un lenguaje malo o miradas hostiles, como frecuentemente es el caso en Inglaterra, donde a las clases bajas se les engaña continuamente en mantener una aversión a los extranjeros gracias a una sucesión diaria ininterrumpida de escritores deshonestos y malvados) (III, 140-141) (abad language or angry looks, as it is often the case in England, where the lower classes are continually deceived into an aversion for foreigners by a daily uninterrupted succession of dishonest and malignant scribblers")).

La proverbial soberbia y ceremoniosa gravedad de los españoles contrastaban con una amabilidad y franqueza en la conversación y un trato llano y hasta democrático entre personas de diferente clase social. En Aranjuez, por ejemplo, conoció a una familia española a cuyas hijas dio varios obsequios, los cuales motivaron el agradecimiento de todos, «sin torpeza, gazmoñeria, descaro ni falsa modestia. Esto empezaba a darme una mejor opinión de los modales [españoles] de la que había tenido antes. Habiendo leído mucho acerca de la soberbia habitual de los españoles, esperaba encontrar un tratamiento raro y ridículo; pero fue una desilusión para mí verles portarse tan bien» (II, 244) («without stiffness, prudery, forwardness, or false modesty. This began to give me a better opinion of [Spanish] manners than I had brought with me. Having read many things of the habitual haughtiness of the Spaniards, I expected some odd and ridiculous treatment; but to my disappointment they behaved very well»). Con referencia a los habitantes de Madrid, su sola preocupación era la de pasar el día del modo más placentero posible; por consiguiente, abundaban las visitas que se hacían unos a otros. Madrid mismo se destacaba por su prosperidad y opulencia, y dado el carácter de sus ciudadanos, se revelaban allí una urbanidad y hospitalidad totalmente libres de una etiqueta rígida o fastidiosa. Era imposible, salvo en la corte, presenciar la extremada formali- 
dad que el resto de Europa alegaba como característica intrinseca del comportamiento hispánico (III, 93).

Se había escrito bastante de que los celos llevaban a los españoles a violentos excesos; aunque posiblemente fuesen los celos causa de muchos crímenes, Baretti, al menos, no pudo comprobar que los españoles fuesen peores en este caso que otras naciones. En una tertulia, reparó, había «cerca de treinta mujeres [que se portaban] con tanta viveza, [que conversaban] con tanta despreocupación con todos los hombres allí presentes» (II, 295) («about thirty ladies [behaving] with such alertness, [speaking] and [being] spoken to with such an unconcernedness by every man theren). En cuanto a él se refería, era risible la indignación expresada por otros viajeros sobre "la inmoralidad" del cortejo. A estos viajeros les convenía olvidar que esta costumbre social era más un juego de charadas que la manifestación de una depravación moral: anécdotas o comentarios sobre amores ilícitos no perjudicaban la venta de ningún libro. En realidad, cada año la usanza era que se escogían dos nombres al azar y a menudo resultaba ser cortejo el marido de su mujer. Como en cualquier país, desde luego, existían tanto la inmoralidad como las virtudes, pero alegar que el cortejo se debía a aquélla era necedad. Baretti sostenía que aquellos individuos que no pensaban respetar sus votos matrimoniales no tenían ninguna necesidad especial del cortejo. Además, para las solteras la esfera de acción que les ofrecía el cortejo estaba muy limitada; la situación de las casadas no variaba mucho, puesto que ellas se hallahan rodeadas de amigas y criadas y asi.tenían pocas posibilidades de actuar con mucha libertad (III, 103 sigs.).

Había, stn duda, casos de españoles que provocaban menosprecio. Los majos, por ejemplo "eran insoportables por sus modales y lenguaje. Les asignaba Baretti una posicion intermedia entre el poissard parisino y el cityspark londinense. Tal vez aun peores eran los oficiales militares. Insolentes, petulantes e ignorantes, ellos llevaron a Baretti a la conclusión de que whay mucha imperiosidad militar en este pais como en cualquier otro... ¡Qué diferencia entre aquellos países y la isla gloriosa de Gran Bretaña, donde ni el coronel, ni el capitán, ni, en efecto, ningún of cial de cualquier rango se alreve a tratar al más misero plebeyo con lal indignidad!n (IV. 98-99) ("much military overbearing takes place in this country, as it does in many others... What a difference between those countries and the glorious isle of Great Britain, where neither Colonel nor Captain, nor indeed any person of any rank whatsoever, dares to treat the meanest plebeian with such indignity!»). 
Baretti elogiaba a los vascos y a los catalanes por su espíritu industrioso e independiente; de los dos, los vascos se señalaban por sus libertades. Cataluña evocaba los Campos Elíseos por su belleza natural y el cultivo de las huertas, y Barcelona era "la ciudad mejor construida que hasta entonces [él había] visto en España» (IV, 76) ("the best built townl [he had] as yet seen in Spain»). Con particular mención a esta capital, el autor descubrió en ella un espíritu emprendedor que hacía posible un estado de desarrollo indudablemente impresionante; sus barrios nuevos eran modelo del ideal ilustrado de urbanismo: «Da placer ver la bonita uniformidad de lo que ya está construido, puesto que las partes de cada casa corren paralelas de cabo a cabo en cada calle. Ninguna casa tiene más de dos pisos, además de la planta baja; y las calles son lo suficientemente anchas para admitir dos y aun tres vehículos de frente. El exterior de cada casa está cubierto de yeso blanco, el cual, habiéndose puesto muy liso, brilla como mármol a medio pulix» (IV, 81-82) ( (It gives pleasure to see pretty uniformity of what is already built, as the parts of every house run parallel from end to end of every street. No house has more than two stories, besides the groundfloor; and the streets are wide enough to admit two and even three vehicles abreast. The outside of every house is covered with white plaster, which, as it was laid on very smooth, shines like marble but half polished")).

Desafortunadamente no todas las ciudades españolas eran como Barcelo na; muchas sólo experimentaban decadencia como, por ejemplo, Toledo. Una visita a esta ciudad fue motivo para que Barelti reflexionase sobre el eclipse del poderío español. Toledo había sido la capital imperial durante los años más gloriosos de España. Desde ella se había dirigido gran parte de la reconquista de la península y la conquista del Nuevo Mundo. Aunque todavía se percibía el vislumbre de su riqueza y grandeza anteriores, había cobrado, debido a una larga y paulatina mengua, casi el tamaño y carácter de una aldea. En tanto que los españoles se habían enfrentado a los moros dentro de la península, razonaba Baretti a la par que sus contemporáneos, se vieron obligados a emprender grandes hazañas. Una vez expulsados los moros y disponible la riqueza de las Indias, con la que se costearon interminables guerras de ningún valor para España, fue inevitable la decadencia (II, 221).

Por cuanto perduraban los vestigios de la grandeza de antaño en la catedral de Toledo, el autor rumiaba:

«Pensemos en los escalones de un altar hecho de plata y de algunas es. tatuas plateadas enriquecidas de diamantes, rubies y esmeraldas! ... Además 
de aquellos escalones de plata, hay una reja muy grande cuyas barras son también de plata... Pues hay tabernáculos, santuarios, ostensorios, lámparas, palmatorias, báculos pastorales, mitras, cálices, crucifijos, relicarios, etcétera, etcétera, algunos de oro y otros de plata, brillando en su mayoría con enormes joyas de las más preciosas, con una infinidad de joyas más pequeñas.. Gran parte de la riqueza [de la catedral], la enumeración de la cual llenaría un volumen grande, se guarda en varias habitaciones y armarios, y solamente se muestra en las fiestas solemnes) (II, 221).

(Think of the steps of an altar made of silver, and of some silver statues enriched with diamonds, rubies, and emeralds! ... Besides those silver steps, there is a very large grate, the bars of which are of silver likewise... Then there are tabernacles, shrines, ostensories, lamps, candlesticks, crosiers, mitres, chalices, crucifixes, reliquaries, etc., etc., some of gold and some of silver, almost all sparkling with large jewels of the most precious kind, with an infinity of small ones... The greatest part of [the cathedral's] riches, the enumeration of which would take a large volume, are kept in several rooms and closets, and protuced only on solemn festivals).

No obstante su admiración, no se refrenó en condenar los males que resultaban de la acumulación de una riqueza infecunda. Según él, no hubiera quien dudara de que la incalculable fortuna atesorada en la catedral sería de gran beneficio al país si se la invirtiera en la agricultura, la industria o el comercio: “¡Qué indignación debe levantarse en el pecho del comerciante necesitado al ver un capital tan grande inútilmente encerrado en una iglesia! ¡Un capital, que llevado al comercio haría opulentos a muchos miles de individuos y feliz a toda la nación! ¡Qué lástima que los españoles no sean sabios!» (II, 199) ("What an indignation must rise in the breast of a needy tradesman at the sight of so large a stock uselessly locked up in a church! A stock, that brought into commerce, would render opulent many thousands of individuals, and the whole nation happy! What a pity the Spaniards are not wise!)). Es de notar que este comentario dirigido a la improductividad de los tesoros de las iglesias y palacios fue uno de los pocos reproches incondicionales que hizo el autor en sus obser. vaciones sobre España.

Tanto en Madrid como en Roma, las dos ciudades europeas con mayor número de iglesias, capillas, oratorios, conventos, monasterios y seminarios, era fácil encontrar mucha ignorancia y superstición, aunque por lo menos en España éstas existían al lado de un espíritu admirable de beneficencia: «Seguramente los españoles merecen algún grado de respeto de parte de todos, sean éstos o no calvinistas, debido a aquella gran caridad que les hizo erigir asilos para la gente afligida por la pobreza y atribulada por las enfermedades. Puede ser que tanto la política como la superstición hayan con- 
tribuido en parte a la construcción de aquellos hospitales... Pero, ¿en que país hallaremos las acciones de los hombres totalmente desecadas de la flaqueza y los vicios humanos?» (II, 302) («Surely the Spaniards are entitled to some degree of respect from all, whether calvinists or not, on account of that extensive benevolence which made them erect asylums to strangers distressed by poverty and afflicted by disease. It may be that policy as well as superstition contributed a share toward the building of those hospitals... But in what country shall we find the actions of men entirely desecated [sic] from human weakness and human vices?)).

Que las mujeres normalmente se inclinaban a acciones y actitudes supersticiosas e intolerantes no se discutía. Una iglesia madrileña ostentaba "una gran porción de un pastel azucarado ofrecido por una dama que se cré́a demasiado aficionada a confites, y un delantal de muselina ofrecido por otra que se encontró en un arranque de orgullo la primera vez que se lo puso» (II, 310) ( (a large fragment of sugar-cake that was presented by a lady who thought herself too fond of sweet-meats, and a muslin apron given by another who caught herself in a fit of pride the first time she put it on»). Obras de esta indole eran risibles y grotescas, pero, aun así, Baretti se preguntaba con cierta ironía la razón por la cual «los metodistas de Inglaterra no han adoptado todavía esta costumbre [de hacer penitencia] en consecuencia de sus rígidas nociones de la mortificación cristiana» (II, 310) ( ( the methodists of England have not yet adopted this practice [of doing penance] in consequence of their rigid notions of Christian mortification s).

Según el autor, su propósito no era el de justificar los males presentes en la vida social y cultural española, vg., la ignorancia, la superstición y la relativa falta de libertad en cuanto a la formación y expresión de ideas. Era indiscutible que la Inquisición había sido y seguía siendo un obstáculo al desarrollo de una España plenamente ilustrada. Por otro lado, los comentaristas extranjeros habían dado deliberadamente a aquellos infortunios un valor excesivo. Exageraban, por ejemplo, la importancia y el impacto del Santo Oficio. Al mismo tiempo que Baretti exponía sus dudas referentes a la eficacia de la censura, le recordaba al lector lo que había dicho un español ilustrado, a saber, que el Indice era absurdo en vista de que a la aristocracia «no se le [daba] un bledo de los anatemas que se fulminaban contra los lectores de libros prohibidos. La clase media no [era] todavía muy estudiosa de las lenguas extranjeras y en cuanto a la gente común, ella... desde luego no se [preocupaba] de la sabiduría francesa) (II, 318319) ("[did] not care a straw for the anathemas fulminated against the 
readers of prohibited books. [The] middling gentry [was] not yet very studious of foreign languages and as to the common people, they... certainly [did] not trouble their heads with French learning”). La censura, sin lugar a dudas, era un impedimento a la ilustración general, pero dadas las circunstancias presentes, era en última instancia bastante ineficaz.

Igual espíritu de exageración junto con una perspectiva simplista cegaron a los viajeros en su valoración de las letras españolas. Se afirmaba que en España no se había escrito nada o casi nada que no fuese sobre teología o moral. Tal desacierto se fundaba en la ignorancia que reinaba referente a España: «Nosotros, vergonzosamente, no hemos hecho caso de los libros de España, al menos recientemente, y no sabemos casi nada de lo que [los españoles] han estado haciendo durante estos últimos doscien. tos años) (III, 10) ( (We have shamefully overlooked the books of Spain, of late at least, and know almost nothing of what they have been doing for these two hundred years»). Era su parecer que tal ignorancia era más deplorable, vistas la riqueza y belleza de la lengua española, indudablemente la más armoniosa de Europa; a pesar de su propia riqueza, el francés y el italiano distaban mucho de alcanzar la sutileza y la sonoridad del español. Estaban justificados, por cierto, aquellos cxíticos que habían censurado a algunos autores españoles su afectación excesiva. Donde aquéllos se excedieron, le parecía a Baretti, era en la conclusión de que una ornamentación tan irremisible era la norma. Góngora y sus imitadores habían caído en ese error, pero el presentarles como modelos para juzgar a toda la literatura española era un desatino (III, 10-18).

Lícito, también, era condenar los autos sacramentales por mezclar "hombres y mujeres... con creaciones alegóricas, con deidades fabulosas, con profetas y santos, con ángeles y diablos, con la Virgen santa y aun con nuestro Salvador mismos» (III, 2I) («men and women... with allegorical creatures, with fabulous dieties, with prophets and saints, with angels and devils, with the blessed Virgin, and even with our Savious himself »). $A$ Dios por razón de estado de Calderón, para citar sólo uno, era una obra malograda hasta en el título que la encabezaba (III, 21). Obras de esta indole aparte, Baretti defendió a Calderón y a otros dramaturgos, tales como Lope de Vega, quienes debían figurar entre los "genios poéticos de primera categoría... [a pesar de] la verbosidad... las descripciones superfluas..., y las frecuentes asociaciones de personajes reales $\mathrm{e}$ ideales» (III, 25-26) ( «very first class of poetical geniuses... [in spite of] prolixity of speech... superfluous descriptions..., and frequent associations of real and ideal personages»). Los entremeses, con toda su «bufonada baja» (III, 41) («low 
buffoonery"), podian igualmente ser apreciados por cuanto causaban hilaridad bien intencionada en el público; al mismo tiempo, los entremeses proporcionaron a Baretti una oportunidad más para atacar a aquellos críticos y autores que le parecían o excesivamente ligados a los unidades clásicas, o demasiado cortos de miras en lo que se refería a su selección de tramas: «En efecto, la presente raza de dramaturgos franceses e ingleses, los más $\operatorname{secos}$ y fríos que ninguna edad teatral jamás haya producido, en vez de descuidar o conrlenar las composiciones dramáticas de España, no harían mal en leer muchas de ellas, sobre todo las de [Lope] de Vega y Calderón, no para imitarlas de ninguna manera, sino para calentar y fecundar sus propias imaginaciones frias y estériles» (IJI, 27) («Indeed the present race of play-wrights in France and England, the driest and coldest that ever any theatrical age produced, instead of neglecting or contemning the dramatick compositions of Spain, would not do amiss to read many of them, especially, those of [Lope] de Vega and Calderon, not to imitate them at all, but to warm and fecundate their own cold and barren imaginations')).

Baretti no designaba al teatro como el único género del que podía sacar algún provecho Europa. La poesía española había experimentado quizás aun más olvido y con menos razones justificables. Lo que aparentemente molestaba a los críticos europeos era la rima asonante española, que ellos culpaban de ser curiosa, antipoética y absurda. En defensa, Baretti tachaha a éstos de ignorantes y pedantes. Estas quejas no hacian más que subrayar su propia pobreza intelectual y, en particular, su incompeteneia frente a la lengua que profesaban conocer: "Si alguno de ellos hubiera dirigido su atención [a la poesia española], posiblemente se habrisn hecho muchos juicios absurdos en lo tocante a este asunto, ya que no se rima de la misma manera en Inglaterra, Francia o Italia» (III, 271-272) ( $\mathrm{Had}$ any of them ever turned his attention [toward Spanish poetry], many an absurd judgement would possibly have been given upon this subject, as the same manner of rhyming is not to be found in England. France, or Italyn). Los que de una manera u otra habian tratado la poesía española le habian hecho un perjuicio, considerando que cla gente no acostumbrada a las peculiaridades extranjeras está a menudo propensa a enjuiciar sin macha ceremonia ni justicia lo que no resulta ser familiars. (III, 27I) (apeople not used to foreign peculiarities are often apt to fall with little ceremony upon whatever they have not been accostumed ton).

Afirmaba de seguido que la literatura española podia jactarse de una variedad y calidad que enriquecerían a otras literaturas, si sólo sus críticos literarios la estudiaran con esmero y objetividad. En el caso de Quevedo, 
no se conocía de su obra fuera de España, más que Los sueños. El haber relegado el resto de su producción literaria al olvido había perjudicado el desarrollo de las letras europeas en general, ya que tanto ellas como los hombres no podian florecer sin recibir y asimismo asimilar influencias de afuera. Por consiguiente, si El Buscón de Quevedo, «un cuadro del vulgo más inicuo y vil, apenas igualado en cualquier otro idioma» (III, 47) («a picture of the wicked and lowest vulgar, scarcely to be matched in any language»), se leyera más extensivamente, mejoraría de seguro el estado general de las letras europeas. En cuanto a los autores contemporáneos españoles, la opinión de Baretti era que no habia mejor genio en la península que Feijoo, a quien clasificaba entre los autores europeos más renombrados de la época. El poco aprecio que había recibido Feijoo provenía del hecho de que no había seguido a ciegas los dictámenes y las preferencias de los que se llamaban a sí mismos guardianes de la excelencia literaria, tanto españoles como extranjeros. Y por cierto que España no carecía de pedantes, como tampoco carecían de ellos otros países europeos: pues, "los críticos menudos españoles le han atacado con severidad [a Feijoo]; y doy por supuesto que a veces han tenido razón; ies tan fácil tener razón a veces cuando se buscan fallos y debilidades, aun en los mejores escritores! No obstante, el genio de Feijoo ha sobrevivido la virulencia malévola de todos los críticos españoles, cuyos comentarios han sido olvidados tan pronto como leídos; lo mismo que en Inglaterra, donde los críticos menudos no son menos abundantes que las ostras y los mejillones» (III, 48-49) («the Spanish minute critics have attacked [Feijoo] severely: and I take it for granted, that sometimes they were right; it is so easy a matter to be right, when hunting for faults and weaknesses even in the best writers! Yet Feijoo's general powers have stood the malignant virulence of all Spanish Reviewers, whose wise remarks have been forgotten as soon as read; just as it happens in England, where minute critics are no less plentiful than oysters and muscles»).

Durante su segundo viaje a España, Baretti descubrió el Fray Gerundio en el que vio mucha semejanza con Don Quijote: «En cuanto a lenguaje y estilo, pocas naciones, a mi humilde parecer, tienen obra mejor [que Fray Gerundio], ... y la edad presente no ha producido ninguna representación más humorística» (III, 56) ( (As to language and style, few nations, in my humble opinion, have anything finer [than Fray Gerundio].... and the present age has not produced a more humorous performancen). Las letras españolas continuaban floreciendo y no solamente en el campo éticoteológico. Se encontraban en España muchas de las mejores traducciones 
de los clásicos greco-latinos. Gran número de éstas, apuntaba Baretti, fueron previamente comisionadas y patrocinadas por Felipe II, «a quien la generalidad de los europeos modernos solamente consideran un rey político $y$ no erudito como lo fue» (III, 43) ( (who by the generality of modern Europeans is only considered as a political King, and not as a learned King, as he was»). De nuevo, Baretti apelaba a la razón y al sentido común. Profesaba poco afecto a Felipe, «uno de los hombres más orgullosos y crueles que jamás haya deshonrado a la humanidad» (III, 260 sigs.) (“one of the proudest and most cruel men that ever disgraced human natures), pero esto no le impidió elogiar del monarca aquellas acciones que él juzgaba dignas de mérito.

Aparte de los clásicos greco-latinos traducidos al español y estudiados dentro de España, el autor mencionaba el esmerado estudio de las letras árabes; en este contexto, nombraba a Miguel Casiri como uno de los más renombrados eruditos en cuestiones de la cultura y civilización musulmanas (III, 59 sigs.). Cualquier noción de que era España un desierto cultural, no respondía a la alegada ignorancia de los españoles, sino a la miopía de los europeos ostensiblemente más eruaditos: "Hay aquí muchos hombres sabios; más tal vez de lo que se dan cuenta los extranjeros, a pesar de que al presente es moda general en varias partes de Europa contarse los hombres unos a otros que los españoles son muy ignorantes» (III, 92). (“There are here many men of knowledge; more perhaps than foreigners are aware of, though it be almost a general fashion at present in several parts of Europe for men to tell each other, that the Spaniards are very ignorant)).

Puesto al lado de la literatura contemporánea de viajes, A Journey from London to Genoa describe una España distinta para el público europeo. El descubrimiento personal de España obró en Baretti una admiración y punto de vista positivo hacia un país que a su parecer había sido sometido a una prensa desfavorable. De ahí que se propusiera rectificar la imagen europea de España al poner en duda los prejuicios y generalizaciones de los viajeros en particular. Su lihro es efectivamente un tratado contra "dos caracterizadores de buen tono de las naciones modernas», («the fashionable characterisers of modern nations»), siendo obligación de hombres ilustrados desenmascarar distorsiones y revelarlas como eran: parciales, absurdas y tendiendo en general a aumentar el desprecio y la antipatía por parte de un sector de la humanidad contra otro. Era indiscutible, para Baretti, que España sufría de muchos males, muchos de ellos muy difíciles de corregir. Sin embargo, ¿no hallaría cualquier hombre razonable, preguntaba, que todos los países eran un compendio de vicios y virtudes? A manera de contestación, evoca- 
ba un dicho que había oído en España: “El diablo no es tan negro como lo pintans (IV, 201). Con referencia a sus propios sentimientos hacia España, ellos se manifestaron en una carta a un amigo, ya de vuelta a Londres en 1769: «Por Dios que me he enamorado de los españoles, gente muy diferente de lo que han escrito infinitos viajeros bribones). ( $\alpha$ Per Dio che mi sono affato innamorato degli spagnuoli, gente molto diversa da quello che infiniti briboni di viaggiatori ne hanno scri(tos) ${ }^{5}$.

\section{Mario Ford Bacrgalupo}

Vanderbilt University

5 Baretti, Epistolario (Bari, 1936), I, 403-404. 